\title{
Improving Colon Cancer Screening in a Resident Ambulatory Clinic
}

Newton Mei, MD

Thomas Jefferson University Hospital

Grace Yang, MD

Thomas Jefferson University Hospital

Mital Shah, MD

Thomas Jefferson University Hospital

Albert Lee, MD

Thomas Jefferson University Hospital

Follow this and additional works at: https://jdc.jefferson.edu/patientsafetyposters

Part of the Medicine and Health Sciences Commons

Let us know how access to this document benefits you

\section{Recommended Citation}

Mei, MD, Newton; Yang, MD, Grace; Shah, MD, Mital; and Lee, MD, Albert, "Improving Colon Cancer Screening in a Resident Ambulatory Clinic" (2017). House Staff Quality Improvement and Patient Safety Conference (2016-2019). Poster 26.

https://jdc.jefferson.edu/patientsafetyposters/26

This Article is brought to you for free and open access by the Jefferson Digital Commons. The Jefferson Digital Commons is a service of Thomas Jefferson University's Center for Teaching and Learning (CTL). The Commons is a showcase for Jefferson books and journals, peer-reviewed scholarly publications, unique historical collections from the University archives, and teaching tools. The Jefferson Digital Commons allows researchers and interested readers anywhere in the world to learn about and keep up to date with Jefferson scholarship. This article has been accepted for inclusion in House Staff Quality Improvement and Patient Safety Conference (2016-2019) by an authorized administrator of the Jefferson Digital Commons. For more information, please contact: JeffersonDigitalCommons@jefferson.edu. 


\section{BACKGROUND}

- Colorectal cancer (CRC) screening has been proven to be a feasible, cost-effective way to reduce incidence of and mortality from CRC.

- $\mathrm{CRC}$ is the second-leading cause of cancer-related death in the United States.

- As early CRC is asymptomatic, it is imperative that we detect it early to reduce mortality.

- Despite the widespread availability of CRC screening, CRC screening rates in our ambulatory sites have been below average.

- The Wednesday Jefferson Hospital Ambulatory Practice (JHAP) resident clinic's CRC screening rate was $44.3 \%$ in September 2016 as compared to an average of $57 \%$ at other ambulatory sites in the Greater Philadelphia region.

Therefore, CRC screening was targeted as an area of quality improvement.

- Our goals were to implement an intervention to improve CRC screening rates in our practice as well as identify sitespecific obstacles to CRC screening that could be intervened on in the future.

- Fecal Immunochemical Test (FIT) is a FDA approved CRC screening modality for one year.

\section{AIM STATEMENT}

Our aim at Wednesday JHAP was to increase the rate of colorectal cancer screenings from $44.3 \%$ to $60 \%$ from September 2016 to May 2017 (9 months)

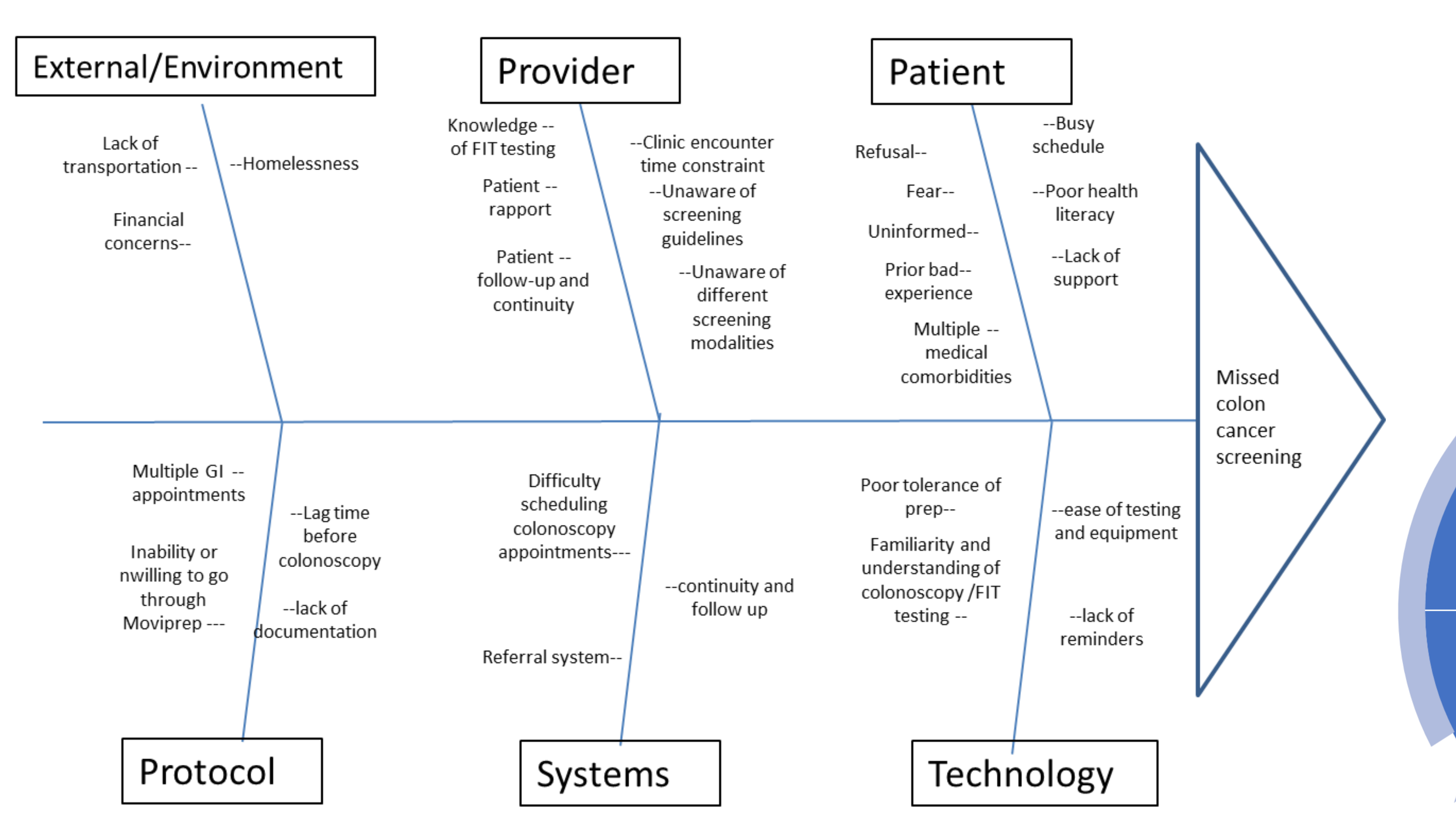

\section{INTERVENTION}

- Our primary intervention was to offer GI referral for colonoscopy, and for patients who refused screening colonoscopy, FIT was offered as an alternative.

- A secondary intervention was educating residents about the importance of colon cancer screening, how to discuss colon cancer screening options with their patients, and how to teach their patients to properly use FIT kits.

- In November 2016, resident physicians started calling patients who were due for CRC screening to arrange CRC screening. Reasons for patient noncompliance or nonadherence were documented.

- Then, since February 2017, patients who still required CRC screening were again contacted via phone and/or mail to set up CRC screening.

From Clinic to
CRC Screening A Process map
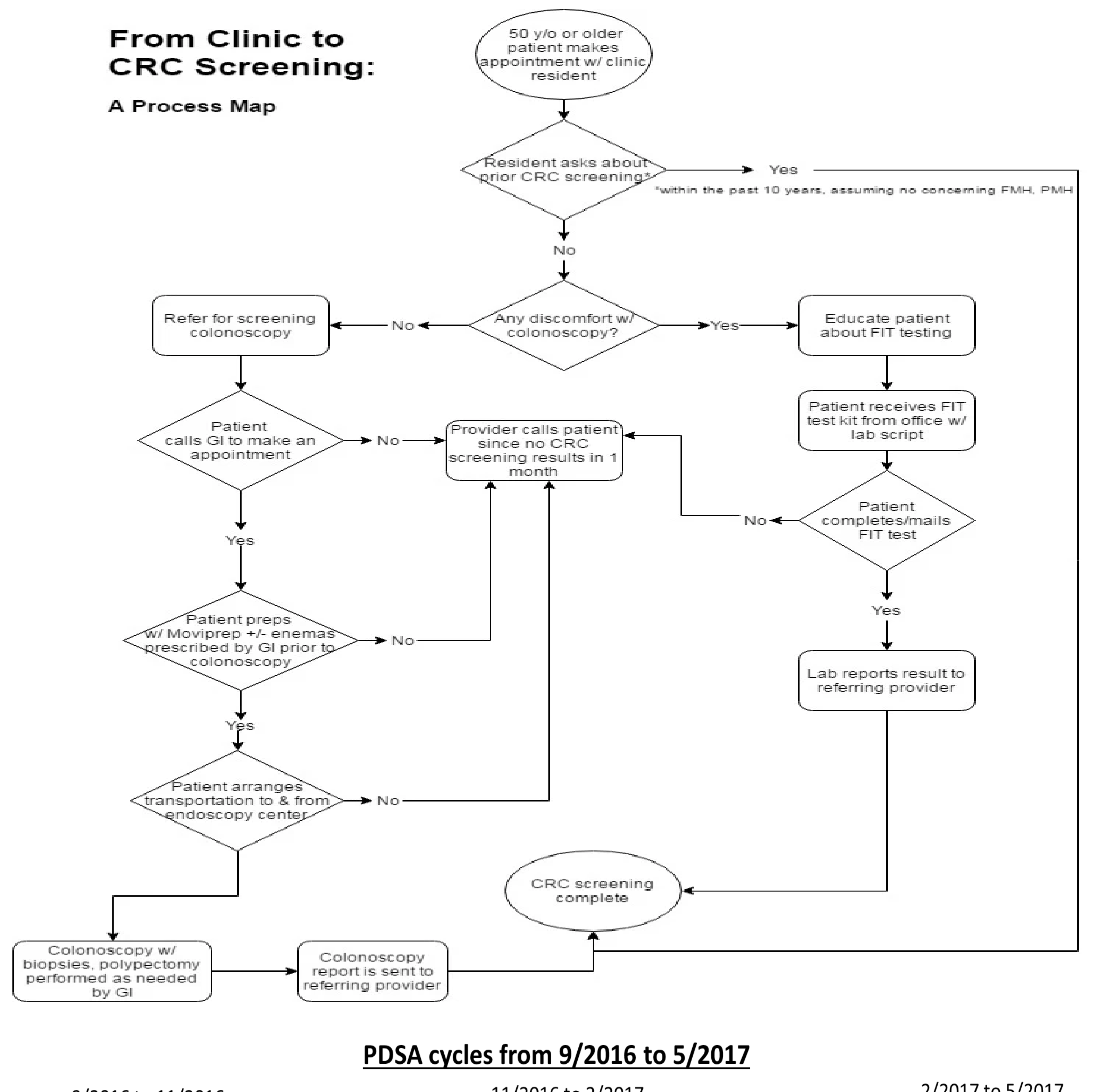

9/2016 to $11 / 2016$
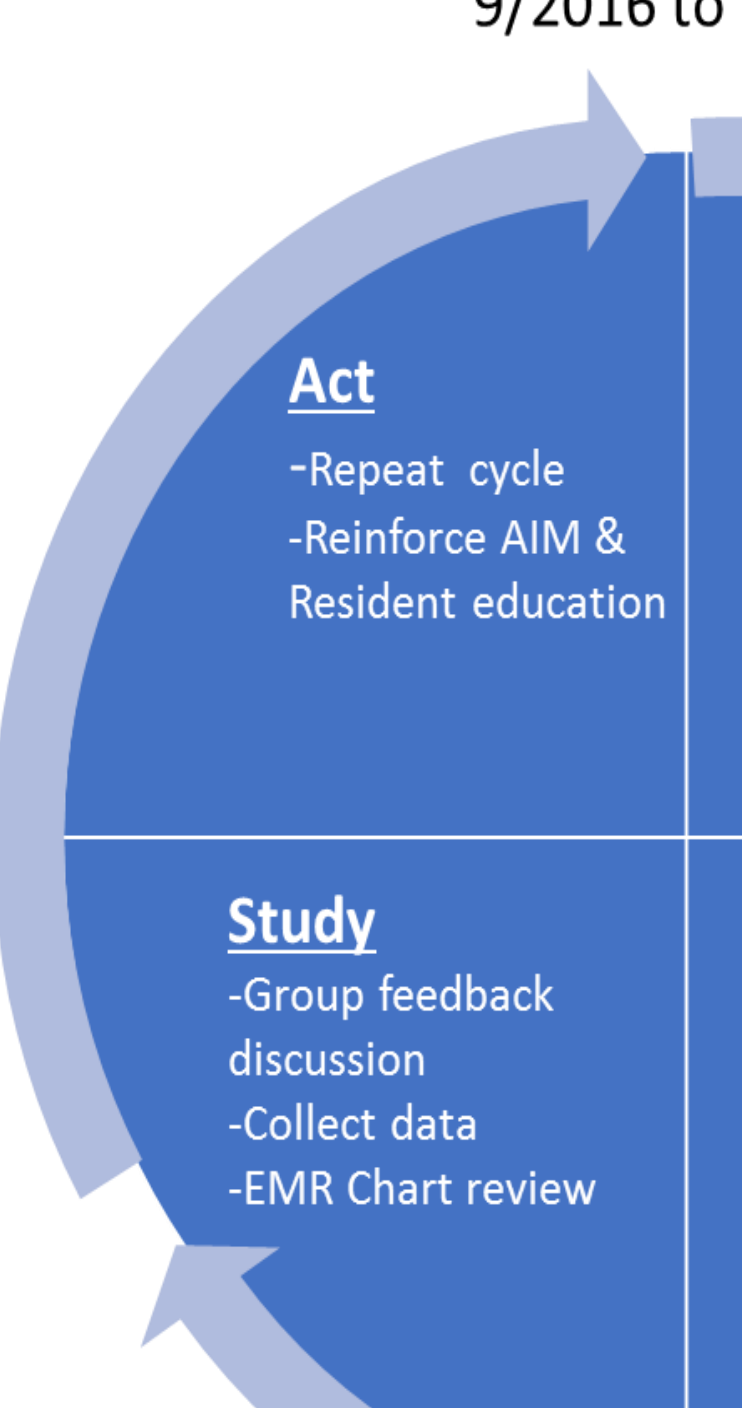

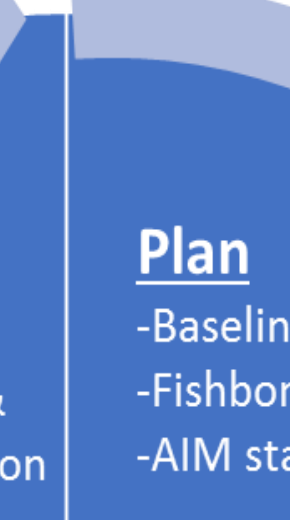

PDSA cycles from 9/2016 to 5/2017

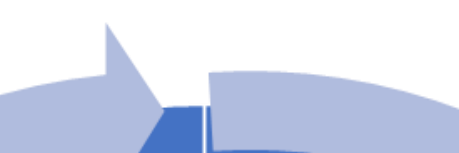

2/2017 to 5/2017

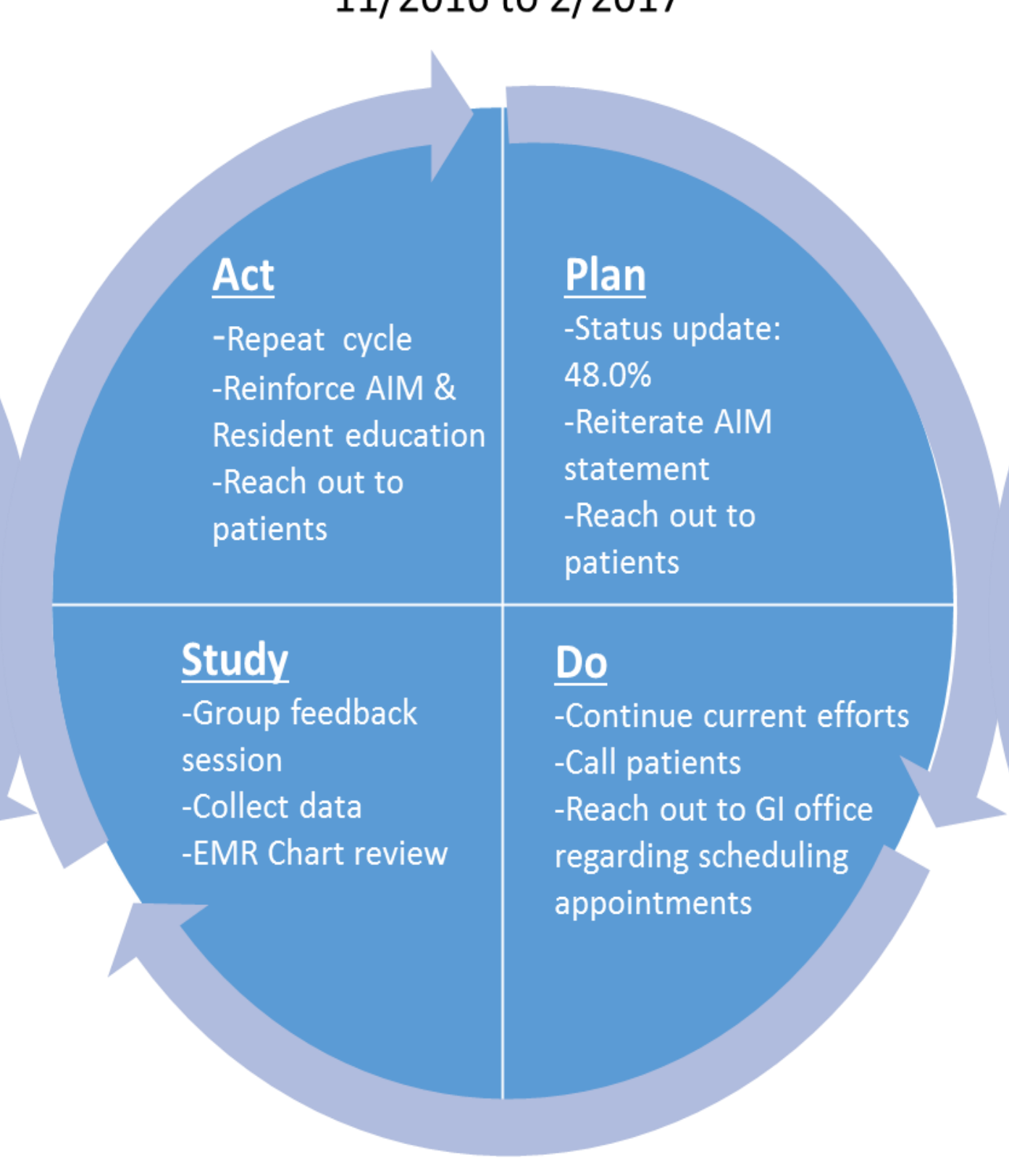

\section{RESULTS}

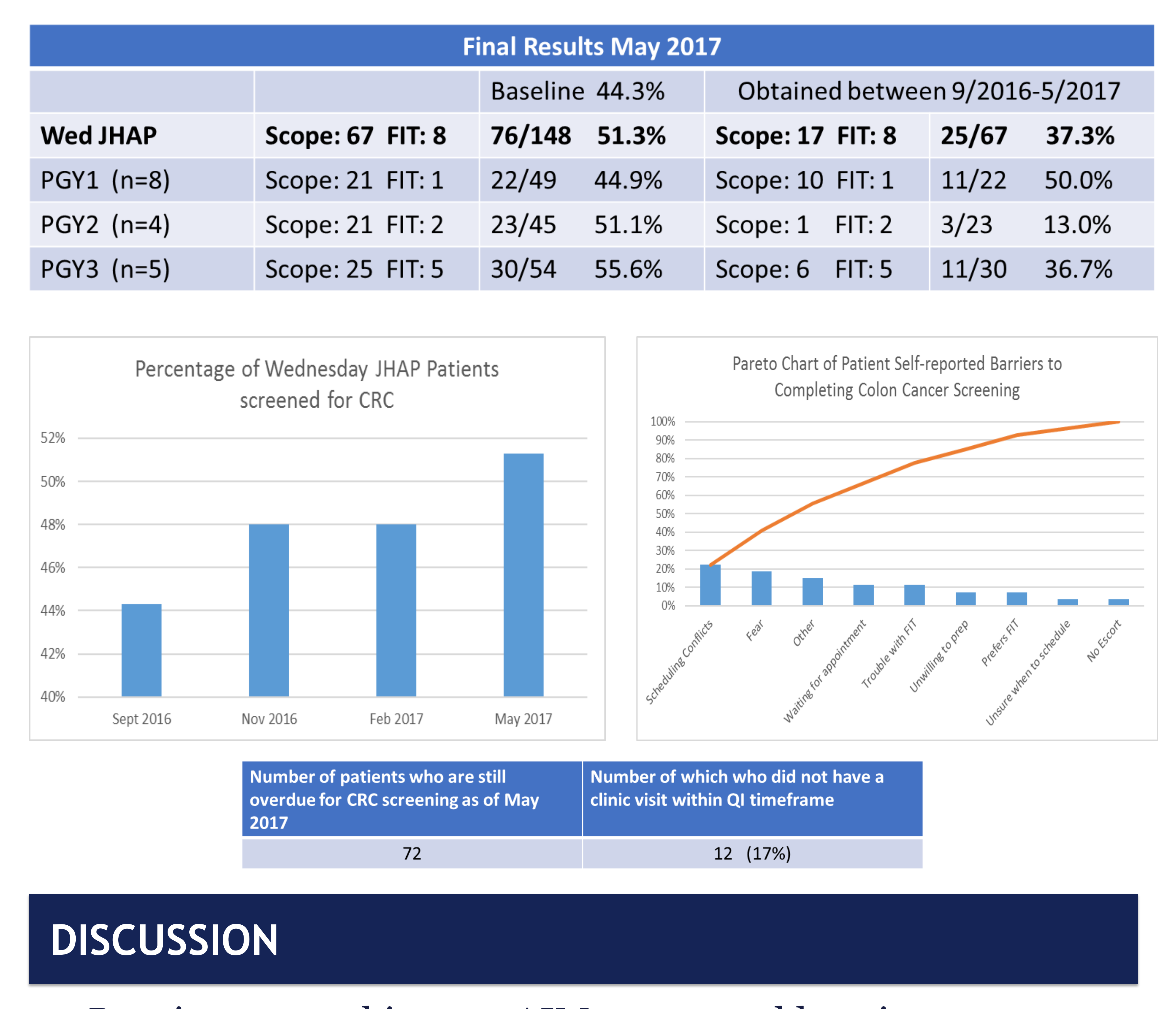

- Despite not reaching our AIM, we were able to increase our colon cancer screening rate by $\mathbf{1 6 \%}$ from 9/2016 to 5/2017

- The most common barrier to colon cancer screening reported was difficulty scheduling a colonoscopy. Future steps include collaborating with GI to develop a more efficient and effective colonoscopy scheduling system and having multiple resident education sessions to train residents on how to effectively educate patients about FIT as an alternative CRC screening option.

- The second most common barrier identified by patients was fear of colonoscopy. We hoped that offering FIT testing would be a suitable alternative for these patients. A future direction is a handout for patients addressing common patient concerns regarding colonoscopy and providing further information to allow for greater patient education and reassurance.

$\frac{\text { Rreferences: }}{1 .}$ Whitlock EP, Lin JS, Liles E, et al. Screening for colorectal cancer: a targeted, updated systematic review for the U.S. 